\title{
Study on Impact Strength of Fly Ash Aggregate Concrete
}

\author{
P.JAYABHARATH ${ }^{1}$, G.KESAVAN $^{2}$ \\ ${ }^{I}$ Civil Engineering, Sri Ramanathan Engineering college, Tirupur, India \\ ${ }^{2}$ Civil Engineering, MizanTeppiUniversity, Ethiopia
}

\begin{abstract}
Results of experimental investigation carried out to study on impact strength of fly ash aggregate concrete are presented in this paper. Aggregate is most widely used in reinforced concrete construction. In this investigation, fly ash aggregates were used in concrete and Impact strength of fly ash aggregate concrete will be studied. The fly ash will be collected in Mettur Thermal Power plant. Then the cement fly ash proportions of 10:90, 12.5:87.5, 15:85, 17.5:82.5, 20:80, and 22.5:77.5 are adopted to get fly ash aggregates. The Particle size distribution, Specific gravity, Bulk density, Impact strength and Crushing strength test are determined. The mix design M20 grade of concrete is adopted by using I.S. method. The fresh concrete tests like Slump test and Compacting factor test will be conducted for the conventional concrete and fly ash aggregate concrete. The semicircular control concrete specimens will be cast and all the specimens will be tested for Impact. The fly ash aggregates also will be tested for impact strength using fly ash aggregate concrete semicircular specimens. The specimens will be cast and cured for 7 days and 28 days and tested for Impact strength. All the test results will be compared with Conventional aggregate concrete.
\end{abstract}

Keywords: Control Concrete, Fly ash Aggregate Concrete, Fly ash Coarse Aggregate, Fly ash Fine Aggregates, Impact Strength.

\section{Introduction}

In conventional concrete, weight of concrete is one of the parameters to compare with weight of fly ash aggregate concrete. Normally density of concrete is in the order of 2200 to $2600 \mathrm{~kg} / \mathrm{m}^{3}$. This heavy self-weight makes an uneconomical structural material compared to low self-weight of fly ash aggregate concrete. In order to produce concrete of desired density to suit the required application, the self-weight of structural and nonstructural members are to be reduced. Hence economy is achieved in the design of supporting structural elements which lead to the development of light weight concrete. Lightweight concrete is defined as a concrete that has been made lighter than the conventional concrete by changing material composition or production method. Lightweight aggregate concrete is the concrete made by replacing the usual material aggregate by lightweight aggregates. Though lightweight concrete can't always substitute normal concrete for its strength potential, it has its own advantages like reduced dead load, and thus economic structures and enhanced seismic resistance, high sound absorption and good fire resistance. Glass fibres in different volume fractions with $25 \%$ and 40\%replacement of cement by fly ash has been used to study the effect on compressive strength, split tensile strength, flexural strength of concrete[1]. Experimental investigation carried out to study the effects of addition of natural san fibres on the fracture toughness and impact strength of high-volume class-f fly ash concrete was reported [2]. Flexural strength of reinforced fly ash aggregate concrete beams was studied [3]. Fine aggregate (sand) was replaced with five percentages $(10 \%, 20 \%, 30 \%, 40 \%$ and $50 \%)$ of class $\mathrm{f}$ fly ash by weight. Tests were performed for properties of fresh concrete. Compressive strength, splitting tensile strength, flexural strength, and modulus of elasticity were determined [4].The compressive strength developments of fly ash aggregate concrete at different ages were studied. The split tensile strength and flexural strength of all the concrete mixes were also investigated at different days of curing [5].However there is no report on the impact strength of fly ash aggregate concrete by cement fly ash proportions. Hence an attempt was made to experimental investigation carried out to study on impact strength of fly ash aggregate concrete by using semicircular specimens from the above six cement fly ash proportions.

\section{Materials}

The following materials were used for preparing the test specimens i) Ordinary Portland cement 43 grade confirming to IS: 8112-1989

ii) Fly ash obtained from Thermal power plant at Mettur, TamilNadu, India. Confirming to IS: 3812-1981

iii) Local river sand confirming to Grading Zone II of IS: 383-1970

iv) Fly ash Fine Aggregate obtained from cement fly ash proportions 10:90, 12.5:87.5, 15:85, 17.5:82.5,20:80 and 22.5:77.5.

v) Hard Broken Granite stone confirming to graded aggregate of size 20mm as per IS: $383-1970$ 
vi) Fly ash Coarse Aggregates obtained from cement fly ash proportions 10:90, 12.5:87.5, 15:85, 17.5:77.5, 20:80 and 22.5:77.5

vii) Bore well water.

\subsection{Specific gravity}

\section{Properties Of Aggregates}

Specific gravity of fly ash aggregate is made use of in design calculations of concrete mixes. With the specific gravity of each constituent known, its weight can be converted in to solid volume and hence a theoretical yield of concrete per unit volume can be calculated. Specific gravity of fly ash aggregate is also required in calculating the compacting factor in connection with the workability measurements. Similarly, Specific gravity of fly ash aggregate is required to be considered when we deal with light weight band heavy weight concrete. The specific gravity of the NSA, NSB, and WGCA aggregates were measured as 1.78, 1.79 respectively.

\subsection{Bulk density}

The bulk density or unit weight of a fly ash aggregate gives valuable information regarding the shape and grading of the aggregate. For a given specific gravity the angular aggregates show a lower bulk density. The bulk density of fly ash aggregate is measured by filling a container of known volume in a standard manner and weighing it. The bulk density depends on the particle size distribution and shape of the particles.

\subsection{Water absorption}

Some of the fly ash aggregates are porous and absorptive. Porosity and absorption of fly ash aggregate will affect the water cement ratio and hence the workability of concrete. The porosity of fly ash aggregate will also the durability of concrete when the concrete is subjected to freezing and thawing and also when the concrete is subjected to chemically aggressive liquids. NSA and NSB had water absorption of about $27 \%$ and $24 \%$ by weight, respectively.

\subsection{Aggregate crushing strength}

The aggregate crushing value gives a relative measure of the resistance of an aggregate to crushing under a gradually applied compressive load. With aggregate of aggregate crushing value 30 or higher, the result may be anomalous and in such cases the ten percent fines value should be determined and used.

\subsection{Aggregate impact strength}

The aggregate impact value gives a relative measure of the resistance of an aggregate to sudden shock or impact. This, in some aggregates differs from its resistance to a slow compressive load. The aggregate impact value should not more than $45 \%$ by weight for aggregate for concrete other than wearing surfaces and $30 \%$ by weight for concrete to be used as wearing surfaces, such as runways, roads and pavements.

\subsection{Particle size distribution}

This is the name given to the operation of dividing a sample of aggregate into various fractions each consisting of particles of the same size. The sieve analysis is conducted to determine the particle size distribution in a sample of aggregate, which we call gradation.

\subsection{Formation of Fly Ash Aggregates}

\section{FLY ASH Aggregates}

The constituents like cement, fly ash and water produce the fly ash aggregates. Water is the binding material that paves the way for the function of the aggregate with good bond property.

\subsection{Proportions for Fly Ash Aggregates}

Cement and fly ash are constituents for preparation of the aggregates. Also water is the binder when it is added to increase the workability. Six different proportions of cement and fly ash such as 10:90, 12.5:87.5, 15:85, 17.5:82.5, 20:80 and 22.5:77.5 were tried.

\subsection{Preparation of Fly Ash Aggregates}

Cement and fly ash were mixed in above six proportions in a concrete mixer. Water was added to the mix by adopting the water cement ratio of 0.3 . The contents were thoroughly mixed in the drum until the complete formation of fly ash aggregates. This method of formation of fly ash aggregates is called pelletisation. The fly ash aggregates are shown in figure 1 . 

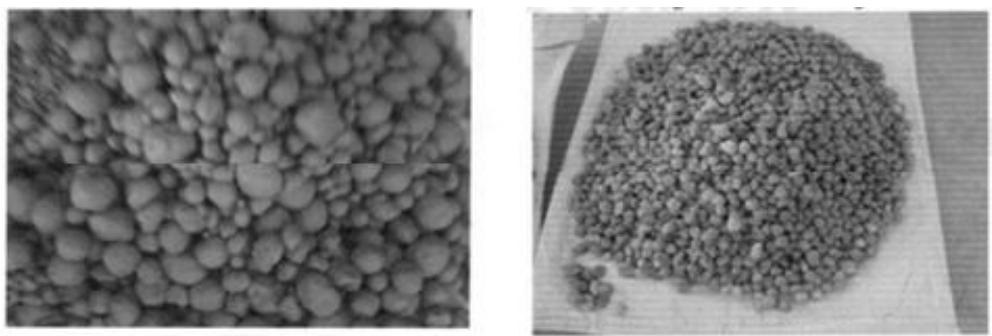

Fig.1 fly ash aggregates

\subsection{Drying and curing of fly ash aggregates}

The fly ash aggregates were taken out from the mixer and allowed to dry for a day. Then the aggregates were cured in a water tank for 7 days.

\subsection{Segregation of fly ash aggregates}

After curing, they were segregated into fine and coarse aggregates based on size of pellets as shown in fig.2.The aggregates having size less than $4.75 \mathrm{~mm}$ were sieved as fine aggregates and size more than $4.75 \mathrm{~mm}$ were sieved as coarse aggregate. From them $20 \mathrm{~mm}$ size coarse aggregates were sieved separately to use them as coarse aggregates

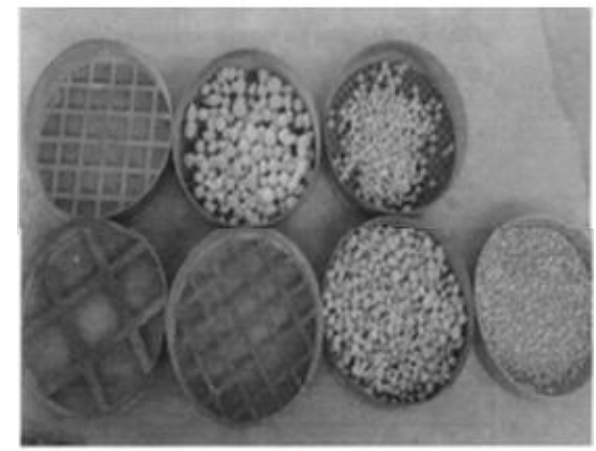

Fig.2 Segregation of fly ash aggregates

\subsection{Concrete mix}

\section{MIX Proportions}

A grade of M20 was designed as per IS method and proportions by weight and volume were arrived. The cement and fly ash six proportions of 10:90, 12.5:87.5, 15:85, 17.5:82.5, 20:80, and 22.5:77.5 will be adopted to get Impact strength.M20 grade of concrete will be adopted. The fresh concrete tests like Slump test \& Compacting factor test will be conducted for the conventional concrete and fly ash aggregate concrete. The semicircular control concrete specimens will be cast and all the specimens will be tested for Impact.The fly ash aggregates also will be tested for impact strength using fly ash aggregate concrete semicircular specimens. The specimens will be cast and cured for 7 days and 28 days and tested for Impact strength. All the test results will be compared with Conventional aggregate concrete.

\subsection{Proportions of fly ash aggregates}

Cement and fly ash are constituents for preparation of the fly ash aggregates. Also water is the binder where it is added to increase the workability. Six different cement fly ash proportions are taken and subjected to pelletisation process as shown in table 1 .

Table 1. Cement fly ash proportions to form fly ash aggregates

\begin{tabular}{|c|c|c|}
\hline TRIAL & CEMENT $(\%)$ & FLY ASH (\%) \\
\hline 1 & 10 & 90 \\
\hline 2 & 12.5 & 87.5 \\
\hline 3 & 15 & 85 \\
\hline 4 & 17.5 & 82.5 \\
\hline 5 & 20 & 80 \\
\hline 6 & 22.5 & 77.5 \\
\hline
\end{tabular}




\section{WORKABILITY TESTS ON FRESH AND FLY ASH CONCRETE \\ 6.1 Slump test}

The mold for the specimen is in the form of the frustum of a cone of bottom diameter $20 \mathrm{~cm}$, top diameter $10 \mathrm{~cm}$ and height $30 \mathrm{~cm}$. The internal surface of the mold is thoroughly cleaned, and placed on a smooth, horizontal rigid and nonabsorbent surface, the mold being firmly held in place when it is being filled. The mold is filled with fresh concrete in flour layers, each approximately one quarter of the height of the mold. Each layer shall be uniformly distributed over the cross section of the mold and for the second and subsequent layer shall penetrate into the underlying layer. After the top layer has been rodded, the concrete is struck off level with a trowel so that mold is exactly filled. The mold is removed from the concrete by raising it slowly in a vertical direction. The concrete subsides and the slump is measured immediately by determining the difference between the height of the mold and the highest point of the specimen being tested and compared that slump value of control concrete and fly ash aggregate concrete as shown in table 2.

Table 2. Comparison of Slump value of control concrete and fly ash aggregate concrete

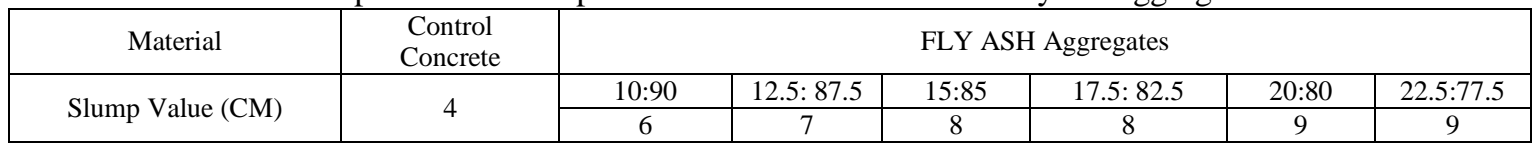

\subsection{Compaction factor test}

This test is more precise and sensitive than the slump test and is useful for concrete mix of very low workability which may consistently fail to slump. The sample of concrete to be tested is placed gently in the upper hopper, using the hand scoop. The hopper is filled level with its brim and the trap door is opened so that the concrete fails into the lower hopper. Immediately after the concrete has come to rest, the trap door of the lower hopper is opened, and the concrete is allowed to fall into the cylinder. The excess of concrete remaining above the level of the top of cylinder is removing by using a trowel and cylinder with the concrete is weighted. The cylinder is than refilled with concreted from the same sample in layer approximately $5 \mathrm{~cm}$ deep, the layers being heavily rammed or vibrated so as to obtain full compaction. The top surface of the fully compacted concrete is carefully struck off level with the top of the cylinder and the cylinder is weighted. The compacting factor is defined as the ratio of the weight of the partially compacted concrete to the weight of fully compacted concrete. Compaction factor of control concrete and fly ash aggregate concrete as compared in table 3.

Table 3. Comparison of Compaction factor of control concrete and fly ash aggregate concrete

\begin{tabular}{|c|c|c|}
\hline \multicolumn{2}{|l|}{ MATERIAL } & COMPACTION FACTOR \\
\hline \multicolumn{2}{|l|}{ CONTROL CONCRETE } & 0.93 \\
\hline \multirow{6}{*}{ FLY ASH AGGREGATES } & 10.90 & 0.88 \\
\hline & $12.5: 87.5$ & 0.91 \\
\hline & $15: 85$ & 0.92 \\
\hline & $17.5: 82.5$ & 0.93 \\
\hline & $20: 80$ & 0.93 \\
\hline & $22.5: 77.5$ & 0.94 \\
\hline
\end{tabular}

\subsection{Impact test on fly ash aggregate concrete}

Impact strength of fly ash aggregate concrete will be determined for semicircular specimens by giving a number of blows by dropping a hammer to strike on a steel ball kept on the specimen. The Impact strength for control concrete specimens will be also calculated and compared concrete specimens.

\subsection{Impact testing machine}

\section{Experimental Investigation}

The impact testing machine (fig.3) consists of a M.S. pipe of diameter $7.5 \mathrm{~cm}$ and height $72 \mathrm{~cm}$ was connected by steel flats with a circular M.S. plate of diameter $30 \mathrm{~cm}$. The circular plate is fixed in position on floor by using bolts and nuts. The impact specimen mold (fig.4) was made up of PVC pipe of diameter $16 \mathrm{~cm}$ and height $6.5 \mathrm{~cm}$ was kept in position on circular plate. A steel ball of diameter $5.5 \mathrm{~cm}$ and weight $0.6 \mathrm{~kg}$ was placed on the impact specimen. A hammer of $6 \mathrm{~cm}$ diameter, $19 \mathrm{~cm}$ height, and $4.4 \mathrm{~kg}$ weight was used to strike the impact specimen. This method of impact test is called Drop weight or falling weight method. 


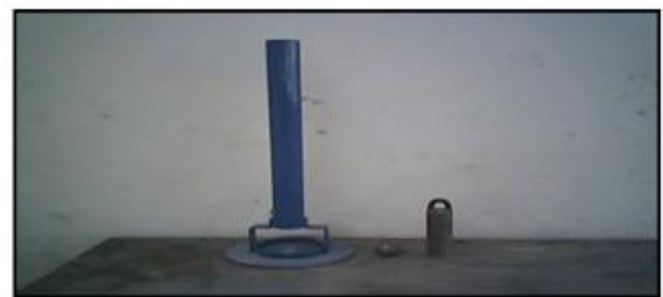

Fig.3 impact testing machine

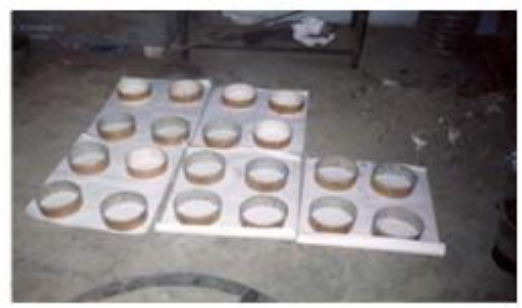

Fig.4 semicircular specimen molds

The cumulative energy imparted to the specimen in $\mathrm{N}-\mathrm{m}$ to cause the ultimate failure was calculated by the following expression.

Cumulative impact energy in N-m Where,

$\begin{array}{lll} & = & \text { mgh } \mathrm{x} \text { Average number of blows } \\ \mathrm{m} & = & \text { mass of the hammer } \\ \mathrm{g} & = & \text { Acceleration due to gravity } \\ \mathrm{h} & = & \text { Height of fall of hammer }\end{array}$

The same procedure was adopted for plain concrete and fly ash aggregate concrete specimens to find the impact strength at 7 and 28 days

\subsection{Impact test result}

The Impact test results of Plain and Fly Ash aggregate concrete specimens of grade M20 were tabulated and shown in tables respectively.

Table 4. Cumulative Impact Energy on the specimens after 7days curing

\begin{tabular}{|c|c|c|c|c|c|c|c|}
\hline \multirow{2}{*}{ MATERIAL } & \multirow{2}{*}{$\begin{array}{l}\text { CONTROL } \\
\text { CONCRETE }\end{array}$} & \multicolumn{6}{|c|}{ FLY ASH AGGREGATES } \\
\hline & & 10:90 & $12.5: 87.5$ & $15: 85$ & 17.5:82.5 & $20: 80$ & $22.5: 77.5$ \\
\hline \multicolumn{8}{|c|}{ AT INITIAL CRACK } \\
\hline NO. OF BLOWS & 45 & 20 & 24 & 50 & 28 & 27 & 27 \\
\hline $\begin{array}{l}\text { CUMULATIVE IMPACT } \\
\text { ENERGY (NM) }\end{array}$ & 369 & 164.02 & 196.82 & 410 & 229.63 & 221.43 & 221.43 \\
\hline \multicolumn{8}{|c|}{ AT FINAL CRACK } \\
\hline NO. OF BLOWS & 52 & 26 & 31 & 58 & 37 & 36 & 35 \\
\hline $\begin{array}{l}\text { CUMULATIVE IMPACT } \\
\text { ENERGY (NM) }\end{array}$ & 426.4 & 213.23 & 254.23 & 475.66 & 303.44 & 295.24 & 287 \\
\hline
\end{tabular}
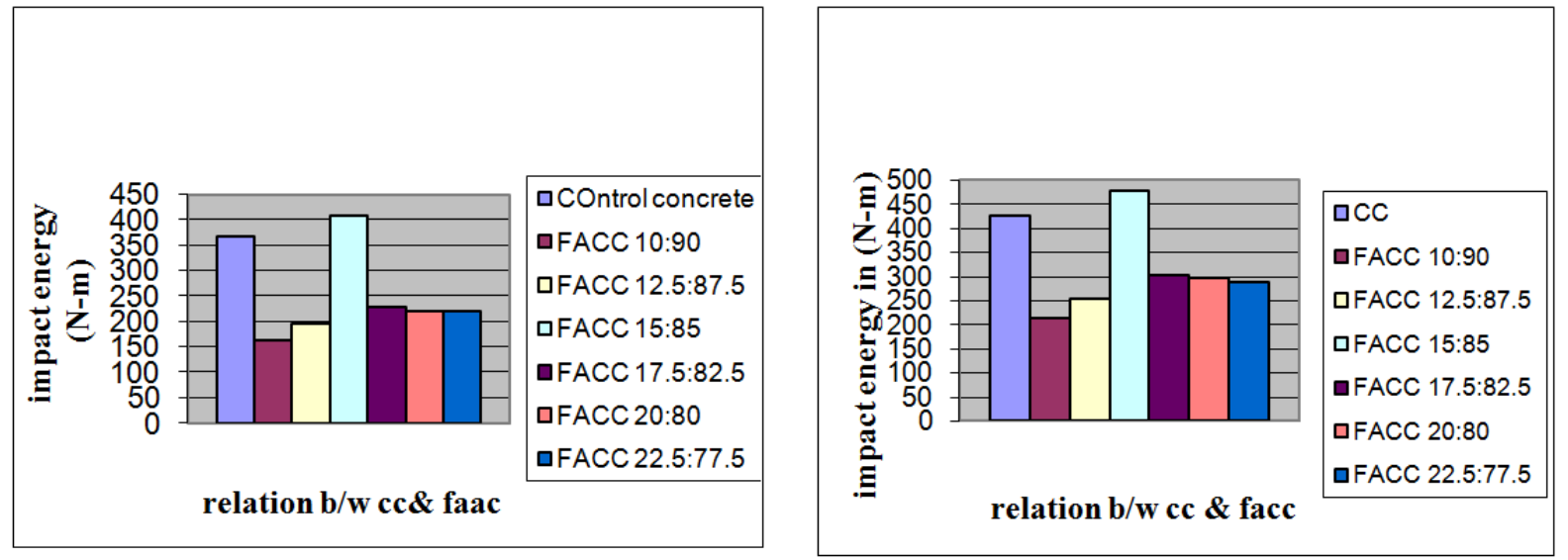

Fig. 5 cumulative impact energy of 7 days curingat initial crack

Fig. 6 cumulative impact energy of 7 days curing at final crack

Table 5. Cumulative Impact Energy on the specimens after 28 days curing

\begin{tabular}{|c|c|c|c|c|c|c|c|}
\hline \multirow{2}{*}{ MATERIAL } & \multirow{2}{*}{$\begin{array}{c}\text { CONTROL } \\
\text { CONCRETE }\end{array}$} & \multicolumn{6}{|c|}{ FLY ASH AGGREGATES } \\
\hline & & 10:90 & $12.5: 87.5$ & $15: 85$ & $17.5: 82.5$ & $20: 80$ & $22.5: 77.5$ \\
\hline \multicolumn{8}{|c|}{ AT INITIAL CRACK } \\
\hline NO. OF BLOWS & 73 & 31 & 36 & 77 & 54 & 49 & 47 \\
\hline $\begin{array}{l}\text { CUMULATIVE IMPACT } \\
\text { ENERGY (NM) }\end{array}$ & 598.68 & 254.23 & 295.24 & 631.5 & 443 & 401.85 & 385.45 \\
\hline
\end{tabular}


Study on Impact Strength of Fly Ash Aggregate Concrete

\begin{tabular}{|l|c|c|c|c|c|c|c|}
\hline NO. OF BLOWS & 106 & 44 & 55 & 112 & 90 & 78 & 72 \\
\hline $\begin{array}{l}\text { CUMULATIVE IMPACT } \\
\text { ENERGY (NM) }\end{array}$ & 869.32 & 360.85 & 451.06 & 918.5 & 738.10 & 640 & 590.48 \\
\hline
\end{tabular}

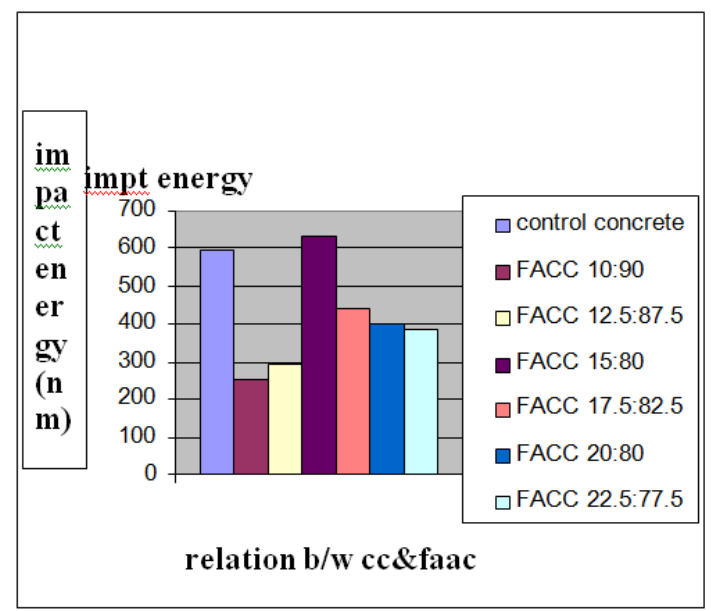

Fig. 7 cumulative impact energy of 28 days curing at initial crack

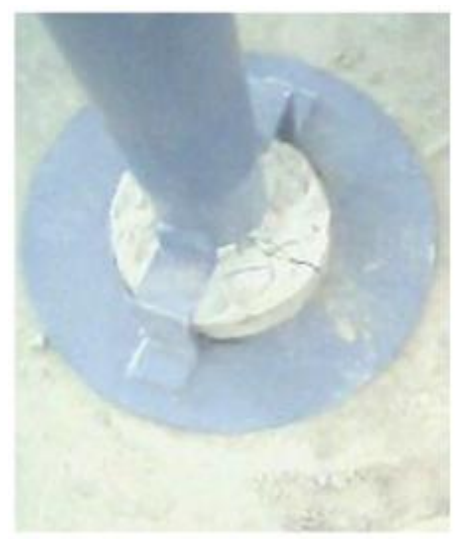

Fig.9 crack at initial stage

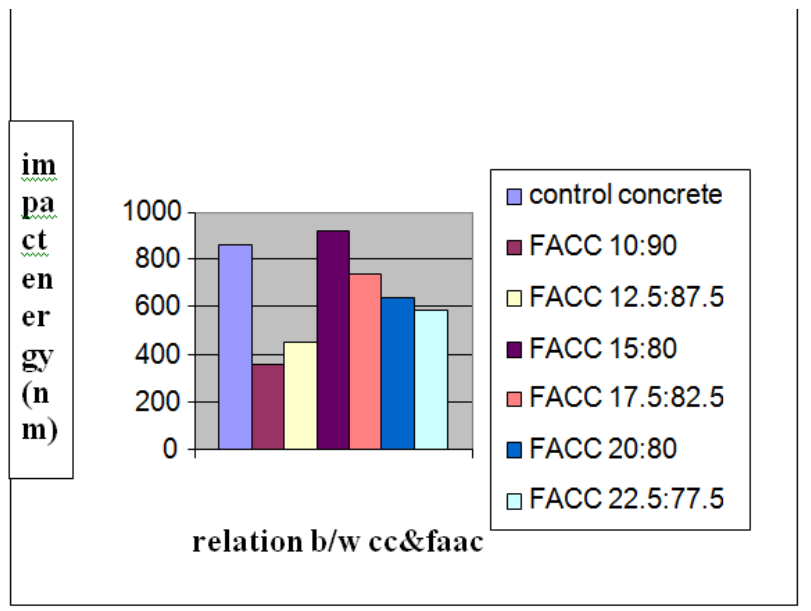

Fig. 8 cumulative impact energy of 28 days curing at final crack

\subsection{Behavior of impact specimens while testing \\ 7.3.1 Impact test of control concrete specimens}

For the control concrete of grade M20, three specimens each were tested at 7 days and 28 days. The hammer was made to strike the specimen from a predetermined height. The blows were given on the specimen continuously until the ultimate failure of specimen occurred. The Ultimate failure of specimen occurred in the form of a crack at the center. The crack at the center propagated on all sides of specimens and the specimens were broken into two halves. It was observed that plain concrete specimens have taken more number of blows as compared to fly ash aggregate concrete specimens.

\subsubsection{Impact test of Fly Ash aggregate concrete specimens}

For the fly ash aggregate concrete of grade M20, three specimens each were tested at 7 days and 28 days. The hammer blows were given continuously until the ultimate failure was observed. The Ultimate failure was observed in the form of a crack on all faces of specimen. The failure pattern was same as that of plain concrete specimens. It was also observed that lesser number of blows were required for fly ash aggregate concrete specimens to reach their ultimate failure as compared to plain concrete specimens.

\section{Results And Discussion}

\subsection{Impact Strength of control concrete Specimens}

Impact strength of control concrete specimens at 7 and 28 days were tabulated. From the results, it was observed that the Impact strength of control concrete at 28 days increased when compared to that at 7 days. 


\subsection{Impact Strength of Fly Ash Aggregate Concrete Specimens}

i) At ratio of 10:90, the Impact strength of fly ash aggregate concrete at 7 days and 28 days decreased by $53 \%$ and $58 \%$ as compared to that of control concrete.

ii) At ratio of 12.5:87.5, the Impact strength of fly ash aggregate concrete at 7 days and 28 days decreased by 43

$\%$ and $49.5 \%$ as compared to that of control concrete.

iii) At ratio of 15:85, the Impact strength of fly ash aggregate concrete at 7 days and 28 days increased by $10 \%$ and $5 \%$ as compared to that of control concrete.

iv) At ratio of 17.5:82.5, the Impact strength of fly ash aggregate concrete at 7 days and 28 days decreased by $33.5 \%$ and $18 \%$ as compared to that of control concrete.

v) At ratio of 20:80, the Impact strength of fly ash aggregate concrete at 7 days and 28 days decreased by 35.5 $\%$ and $29.5 \%$ as compared to that of control concrete.

vi) At ratio of 22.5:77.5, the Impact strength of fly ash aggregate concrete at 7 days and 28 days decreased by $36.5 \%$ and $34 \%$ as compared to that of control concrete.

\section{Conclusion}

Based on the test results, the following conclusions were drawn

i) The Impact strength of fly ash aggregate concrete with cement fly ash proportions 15:85 at 7 and 28 days increased by $10 \%$ and $5 \%$ as compared to that of plain concrete.

ii) The Impact strength of fly ash aggregate concrete at 7 and 28 days for all other fly ash aggregate concrete with cement fly ash proportions ratios of 10:90, 12.5:87.5, 17.5:82.5, 20:80, 22.5:77.5 was observed less when compared to that of control concrete.

iii) All fly ash aggregate concrete with various cement fly ash proportions showed high impact strength at 28 days when compared 7 days.

iv) Similarly in control concrete also high impact strength at 28 days was observed when compared 7 days.

v) Considering the noise pollution and vibrations caused due to blasting of rocks to get coarse aggregates are found a suitable alternative material.

vi) Considering the erosion of river bed and the ever escalating cost of sand, the fly ash fine aggregate may be consider as a suitable alternative material.

vii) Only a limited quantity of fly ash utilized for construction works, when fly ash is used as aggregates in concrete more effective utilization of fly ash is possible.

\section{Acknowledgement}

The authors express their sincere thanks to Dr.S.ShanmugaSundaram, Professor and Head of the Department, Department of Civil Engineering, Excel Engineering College, pallakkapalayam, komarapalayam, Namakkal, and TamilNadu, India.For the support he has provided to carry out this experimental investigation.

\section{Journal Papers:}

\section{References}

[1]. Rama Mohan Rao,P., SudarsanaRao,H., Sekar,S.K., " Effect of Glass Fibres on Flyash Based Concrete", International Journal of Civil and Structural Engineering, Volume 1, No 3, 2010.

[2]. RafatSiddique, "Fracture Toughness and Impact Strength of High-Volume Class-F Fly Ash Concrete Reinforced with Natural San Fibres", Leonardo Electronic Journal of Practices and Technologies ISSN 1583-1078 Issue 12, January-June 2008 p. 25-36.

[3]. Sudhakar, G.Viwanathan, B.Dineshkumar,"Study on Flexural Strength of Reinforced Fly ash Aggregate Concrete Beams", $3^{\text {rd }}$ International Conference on Recent Innovations in Science, Engineering and Management (ICRISEM 16), ISBN:978-81-932074-1-3.

[4]. RafatSiddique, "Effect of fine aggregate replacement with Class F fly ash on the mechanical properties of concrete", Cement and Concrete Research 33 (2003) 539-547.

[5]. S.Shanmugasundaram, Dr. S.Jayanthi, Dr. R.Sundararajan, Dr.C.Umarani, Dr. K.Jagadeesan, "Study on Utilization of Fly Ash Aggregates in Concrete", Modern Applied Science Vol. 4, No. 5; May 2010.

[6]. Silvia collepardi, Luigi coppola , Roberto troli (2007) "Influence of the super plasticizer type on the compressive strength of reactive powder concrete for precast structures”, International journal of Civil engineering,Vol.3,pp.55-60.

[7]. Srinivasa Rio, Sephardim Sekhar (2008)“Impact Strength andWorkabiltyBehaviour of Glass Fibre Self Compacting Concrete", International Journal of Mechanics and Solids, Vol.3,pp.61-74.

[8]. Sathiar.R., Ganesh Babu.K., Manu Santhanam(2008),“ Durability study of low calcium fly ash geopolymer concrete", Cement and Concrete Research, vol.4,pp.540-546.

[9]. Bentz.DP (2011)"Thermal properties of high-volume fly ash mortars and concretes" Journal of Building Physics,vol.3,pp. 263-275.

[10]. Rama Mohan Rao,P., SudarsanaRao,H., Sekar,S.K., (2010), "Effect of glass fibres on flyash based concrete", International journal of civil and structural engineering,Vol.3,606-612. 
[11]. Bressan,J.D., Efftin,C., Tramontin,A.,(2008),"Fracture toughness and strength of fly ash concrete”, Materials and Structures, v.23, (1991), pp.457-460.

[12]. Shardadadse,Pramilakumari,"Fly ash characterization ,utilization and government initiatives in India",Journal of scientific and industrial research, Vol.67,pp.11-18.

\section{Books}

[13]. M.S. Shetty, concrete technology theory and practical, Reprint, 2005 Publishers S. Chand and Company Ltd., New Delhi.

[14]. Neville, A.M., and Brooks, J.J. concrete technology, ELBS, 1987. 